\title{
Determinants of Choice of Transportation Mode for White Petroleum by Oil Marketing Companies in Kenya
}

\author{
Samwel odoyo Mikwa Owuor
}

\begin{abstract}
Due to an increasingly competitive market, transportation mode of petroleum products is usually considered as one of the major bottlenecks in the supply chain of white petroleum. Liberalization of the petroleum industry saw an end to Kenya Pipeline Company's (KPC) monopoly in transportation of white petroleum fuels in the country. As a result, oil marketing companies (OMCs) are free to choose preferred modes of transportation, which can either be pipeline, rail or road. This study establishes the choice of transportation mode for white petroleum by OMCs in Nairobi, Kenya by looking at determinants such as company profile, time, quality, safety and storage facilities, as well as the influence of these on the choice of transportation mode. This was a descriptive research design conducted among oil marketers in Kenya. Kenya has about 58 oil-marketing companies that participate in the importation of white petroleum products and the study covered $50 \%$ of the total OMCs in Nairobi. Data collected was purely quantitative and it was analyzed by descriptive analysis. The data was analyzed using statistical package for social sciences (SPSS) version 18 and Microsoft Excel to generate quantitative reports through tabulations, percentages, and measures of central tendency. The study found out that cost of service, quality of petroleum products delivered and environmental factors on health, safety and security are the key determinants of choice of transportation mode of white petroleum products by OMCs in Nairobi. The study also found out that the company profile of the OMCs does not influence their choice of transportation mode, while turnaround time is an important factor but considered alongside other factors when determining the choice of transportation mode of white petroleum as it is considered alongside other factors.
\end{abstract}

\section{Introduction}

Over the past decades, the growth of globalization has caused an expansion in trade demand, and logistic activities have become important issues. At present, improvements in logistics have been the primary source of increased profits for companies, allowing them to maintain their competitive advantage (Taniguchi and Thompson, 2003).

A key decision in logistics management is the selection of the transportation mode and carrier to move a firm's inbound and outbound freight. Managers typically consider multiple attributes when making this decision, often focusing on cost and transit time as the primary criteria. This is not a trivial decision, however, as the process often involves multiple criteria, some of which are not readily quantified. Additionally, the importance of individual factors often differs from industry to industry, company to company, and even within a company from one facility to the next. Consequently, mode and carrier selection is often viewed differently for inbound and outbound shipments, even at the same location.

Mode choice and carrier selection are part of the decision-making process in transportation that includes identifying relevant transportation performance variables, selecting mode of transport and carrier, negotiating rates and service levels, and evaluating carrier performance (Moncket al., 2005). No doubt, these are all important decisions for logistics managers. Within manufacturing firms, transportation costs average 20 percent of total production costs (Russell and Taylor, 2003). For the Norwegian companies surveyed in Pedersen and Gray (1998), more than 50 percent of the total logistics cost of a product is attributed to transportation. However, transportation is more than an incurred cost, as transportation and distribution can be instrumental in achieving competitive advantage (Reimann, 1989). The performance of the transport carrier may influence the effectiveness of the entire logistics function of a company. It follows that the process of selecting an appropriate transport carrier is important to the firm's success.

As noted by Ronald H. Ballou (1999) transportation is the most important single element in logistics costs for most companies. Thus the logistician needs a good understanding of transportation matters. He further describes the importance of an effective transportation as a system which contributes to greater competition in the market place, greater economies of scale in production, and reduced prices for goods (Ibid.1999).

Devid Frederick Ross (2000) defined a number of performance characteristics that OMCs must consider when selecting the appropriate mode of transportation. These characteristics must be matched with the type and quantity of product to be shipped, the capacities and capabilities of the transportation mode, and relevant cost issues (Ibid.2000). 
Transportation can have significant effects on mobility, economic development, environmental quality, government finance and the quality of life. Wise planning is needed to help create high quality transportation facilities and services at a reasonable cost with minimal environmental impact and to enhance economic activity. Failure to plan can lead to severe traffic congestion, dangerous travel patterns, slow economic growth, adverse environmental impact and wasteful use of money and resources. Transportation planning is required by federal and state law in order to receive most types of federal, state and local funding for transportation projects. Significant transportation projects require a long lead time for their design and construction. Furthermore they can have major effects on future land use patterns which need to be assessed.

Due to an increasingly competitive market, transportation operations are usually considered as one of the major bottlenecks in the oil production chain. Thus, OMCs are eager to find ways to pursue efficient transportation schedules within their operational planning so as to organize their activities to achieve better competitive advantages. To efficiently manage the available resources is, in other words, to have their products at the right price, in the right quantity, at the right place and at the right time.

The importance of petroleum products to Kenya can only be fully appreciated when one realizes the dominant role they play in our economy. Petroleum products are very strategic to the various sectors of the Kenyan economy such as industries, transportation, and aviation among others. Crude petroleum is white petroleum which is used to give a variety of petroleum products including gasoline, diesel, kerosene, liquefied petroleum gas, aviation fuel, lubricating oils, waxes, fuel oil, Bitumen/Asphalt, industrial chemicals solvents, insecticides, and agrochemicals, among others (Burke, 1973). White petroleum used in Kenya is distributed in Kenya by pipeline, rail or road.

Many logistics managers of OMCs are faced with options of choosing between pipeline, road or rail transportation for white petroleum. More recently this problem was merely a cost minimization problem; cost was mainly understood as "out of pocket" cost. The increasing pressures for fast delivery of small batches, the possibility of direct access to the final customer and various other reasons have favored road transportation in the years past. Currently, problems of overloaded roads, multiple traffic accidents and uncontrollable emissions come with other challenges such as waiting cost, environmental damage, company image and regulatory elements.

Mode and carrier selection have become increasingly complex. Historically, carrier selection has been structured as a two-step process, first the choice of the mode, followed by the selection of the carrier within that mode. These decisions today are often made simultaneously, along with the alternative of outsourcing to thirdparty logistics organizations. Deregulation of the rail and trucking industries, implementation of innovative manufacturing strategies such as just in time delivery, and increased emphasis on quality management have all made the transportation choice problem more complex.

Distribution of petroleum products in Kenya to end users has predominantly been through Pipeline, Road and Rail. The primary mode of transport for fuels in the country today is through the pipeline, managed by a government parastatal, Kenya Pipeline Company. It is estimated that the demand between Mombasa and Nairobi through the pipeline is approximately $700 \mathrm{~m}^{3} / \mathrm{hr}$. whereas it currently operates at an average throughput of $450 \mathrm{~m}^{3} / \mathrm{hr}$. (vs. actual capacity of $810 \mathrm{~m}^{3} / \mathrm{hr}$.). At this rate of clearance, KPC is only able to create $324,000 \mathrm{~m}^{3}$ of ullage per month at the Kipevu Oil Storage Facility (KOSF) Import Terminal despite having an installed capacity to clear $576,000 \mathrm{~m}^{3}$ per month). Further, the pipeline from Nairobi to Western Kenya operates at a maximum capacity of $220 \mathrm{~m}^{3} / \mathrm{hr}$. against an estimated demand of at least $400 \mathrm{~m}^{3} / \mathrm{hr}$.

KPC works with the Government in the implementation of key projects such as the extension of the Oil Pipeline to Uganda and the LPG import handling and storage facilities. It also assists in the fight against fuel adulteration and dumping, not forgetting that it is also charged with the responsibility of ensuring the efficient operation of the petroleum sub-sector.

Unlike some state corporations, KPC does not depend on Government subsidies, but is a source of revenue to the Government in terms of dividends and taxes. The overall objective of setting up the company was to provide the economy with the most efficient, reliable, and safe and least expensive means of transporting petroleum products from Mombasa to mainland.

Kenya has about 58 oil-marketing companies that participate in the importation of white petroleum products whose total demand is approximately 500 million litres a month for Kenya and Uganda. The Open Tender System (OTS) is the primary method for sourcing of petroleum products into Kenya. Since the OTS is run through monthly tenders, it entails sourcing of petroleum predominantly from the spot market whereby petroleum is sourced from the open market without any prior contracts. The OMCs currently in operation in the country include Vivo Energy, Kenol Kobil, Galana Oil, Oil Libya, Total, Gulf, Hashi, NOCK, ADDAX, Hass, Bakri, Gapco, Petro and Fossil, that commands over $80 \%$ of the market with the rest of the OMCs serving $20 \%$ of the market. The available ullage at KPC of approximately 324 million litres a month has to be shared among the OMCs. The shortfall, 180 million litres, must be delivered by other modes of transport, i.e. by Road or Rail and through private depots at Mombasa. 
In the present research we aimed at:

i. establishing how Oil Marketing Company's profile influences choice of transportation mode of white petroleum products by oil marketers in Nairobi.

ii. determining how turnaround time in receiving products influences choice of transportation mode of white petroleum products by oil marketers in Nairobi.

iii. finding out if the cost of service influences choice of transportation mode of white petroleum products by oil marketers in Nairobi.

iv. establishing how quality of petroleum products influence choice of transportation mode of white petroleum products by oil marketers in Nairobi.

v. determining how environmental factors (health, safety and security) on handling of petroleum products influence choice of transportation mode of white petroleum products by oil marketers in Nairobi.

\section{Significance of the Study}

This study was intended at benefiting OMCs and other transporters in determining the most convenient and preferred mode of transporting white petroleum products in Nairobi. This was to go a long way to assist the oil marketers identify factors that affect their business performance, strengths, weakness, opportunities, threats and how to re-define its policy strategy in relation to transportation of white petroleum. The findings of the study will be used by the OMCs and other transporters to serve as a benchmark in setting certain standards for improvement on their supply of white petroleum in meeting customers' needs. The policy makers and government can use the findings to come up with the policies geared towards ensuring the transportation modes effectively contribute to efficient supply of white petroleum products in the country. Transaction Cost Economics (TCE)

The first theory, Williamson's (1975) transaction-cost economics, a combination of economic theory and management theory, according to Humphreys et al. (2002, p. 568), and attributed to earlier thoughts by Coase (1937), tells that the characteristics of a transaction - frequency of transactions, asset specificity, uncertainty in demand, limited rationality and opportunistic behavior - determine the most efficient governance structure: market, hierarchy or hybrid (i.e. a collaborative arrangement).

Geyskens et al. (2006, p. 531) provide evidence for this theory by their analysis of other primary studies and state that the make-or-buy decision is mostly related to uncertainty. Others have focused on methods for decision making. For example, Humphreys et al. (2002, pp. 572-3) introduce a knowledge-based system with the fifth step being based on transaction-cost economics. Dyer (1997) uses transaction-cost economics to explain differences between Japanese and US practices. Fill and Visser (2000, p. 46) and McIvor (2000b, 2003) base their research into outsourcing on transaction-cost economics combined with the core competencies approach. The studies mentioned serve as examples for those that deploy transaction-cost economics for setting out approaches to decision making on outsourcing.

TCE theory at its core focuses on the costs of completing transactions by one institutional mode rather than another (Williamson, 1975). The transaction, a transfer of a good or service, is the unit of analysis. The primary assumptions are bounded rationality and opportunism which cause transactional difficulties. The theory and empirical studies claim that transaction difficulties and associated cost increase when transactions are characterized by three main attributes: asset specificity, uncertainty and frequency of the transaction.

Resource Based View: Discussions on RBV of the firm begin with Wernerfelt's (1984) "A resource-based view of the firm," by analyzing firms from the resource side rather than from the product side. Following Wernerfelt's article, Barney (1991) proposes a framework, called the RBV of the firm to study a firm's internal strengths and weaknesses. Assumptions of the RBV are heterogeneous and immobility. Firm resources are controlled by a firm and that enables the firm to conceive and implement strategies designed to improve its efficiency and effectiveness (Barney, 2007). As the RBV of the firm developed, scholars have started a series of discussions on boundary choices, core competencies and competitive advantages.

Supply Chain Management (SCM) Theory: The term Supply Chain Management "SCM" was first used by Oliver and Webber in 1982 and was developed from logistics point of view. A number of researchers discuss logistics outsourcing from SCM point of view. Rao and Young (1994) and Van Damme and Van Amstel (1996) suggest that firms consider outsourcing of logistics to an external LSP when logistics complexity is high. Wilding and Juriado (2004) observe that cost reduction is the main motivation for logistics outsourcing. Bolumole (2001), mentions that firms which outsource for operational and cost-based reasons will tend to restrict LSPs' involvement to the basic logistics functions.

Consumer Behaviour and Consumer Decision Making: Consumer decision making has long been of interest to researchers. Beginning about 300 years ago early economists, led by Nicholas Bernoulli, John von Neumann 
and Oskar Morgenstern, started to examine the basis of consumer decision making (Richarme, 2007). This early work approached the topic from an economic perspective, and focused solely on the act of purchase (Loudon and Della Bitta 1993). The most prevalent model from this perspective is 'Utility Theory' which proposes that consumers make choices based on the expected outcomes of their decisions. Consumers are viewed as rational decision makers who are only concerned with self-interest (Schiffman and Kanuk 2007, Zinkhan 1992).

Where utility theory views the consumer as a 'rational economic man' (Zinkhan 1992), contemporary research on Consumer Behaviour considers a wide range of factors influencing the consumer, and acknowledges a broad range of consumption activities beyond purchasing. These activities commonly include: need recognition, information search, evaluation of alternatives, the building of purchase intention, and the act of purchasing, consumption, and finally disposal. This more complete view of consumer behaviour has evolved through a number of discernable stages over the past century in light of new research methodologies and paradigmatic approaches being adopted.

While this evolution has been continuous, it is only since the 1950's that the notion of consumer behaviour has responded to the conception and growth of modern marketing to encompass the more holistic range of activities that impact upon the consumer decision (Blackwell, Miniard et al., 2001). This is evident in contemporary definitions of consumer behaviour:

"Consumer behaviour..... is the study of the processes involved when individuals or groups select, purchase, use or dispose of products, services, ideas or experiences to satisfy needs and desires." (Solomon, Bamossy et al. 2006, p6).

Theoretical Approaches to the Study of Consumer Behaviour: A number of different approaches have been adopted in the study of decision making, drawing on differing traditions of psychology. Writers suggest different typological classifications of these works with five major approaches emerging. Each of these five approaches posit alternate models of man, and emphasize the need to examine quite different variables (Foxall 1990); they will briefly be introduced in turn. They are the economic man, psychodynamic, behaviourist, cognitive and humanistic.

Economic Man: Early research regarded man as entirely rational and self-interested, making decisions based upon the ability to maximise utility whilst expending the minimum effort. While work in this area began around 300 years ago (Richarme, 2007), the term 'economic man' (or even Homo economicus (Persky, 1995)) was first used in the late 19th century (Persky, 1995) at the start of more sustained research in the area.

In order to behave rationally in the economic sense, as this approach suggests, a consumer would have to be aware of all the available consumption options, be capable of correctly rating each alternative and be available to select the optimum course of action (Schiffman and Kanuk, 2007). These steps are no longer seen to be a realistic account of human decision making, as consumers rarely have adequate information, motivation or time to make such a 'perfect' decision and are often acted upon by less rational influences such as social relationships and values (Simon, 1997). Furthermore, individuals are often described as seeking satisfactory rather than optimum choices, as highlighted by Herbert Simons Satisficing Theory (Simon 1997), or Kahneman and Tversky's Prospect Theory (Kahneman and Tversky, 1979) which embrace bounded rationality (Simon, 1991).

Psychodynamic Approach: The psychodynamic tradition within psychology is widely attributed to the work of Sigmund Freud (1856-1939) (Stewart, 1994). This view posits that behaviour is subject to biological influence through 'instinctive forces' or 'drives' which act outside of conscious thought (Arnold, Robertson et al., 1991). While Freud identified three facets of the psyche, namely the Id, the Ego and the Superego (Freud, 1923), other theorists working within this tradition, most notably Jung, identified different drives (Ribeaux and Poppleton, 1978).

Behaviourist Approach: In 1920 John B. Watson published a landmark study into behaviour which became known as 'Little Albert' (Watson and Rayner, 1920). This study involved teaching a small child (Albert) to fear otherwise benign objects through repeated pairing with loud noises. The study proved that behaviour can be learned by external events and thus largely discredited the Psychodynamic approach that was predominant at the time.

Essentially behaviourism is a family of philosophies stating that behaviour is explained by external events, and that all things that organisms do, including actions, thoughts and feelings can be regarded as behaviours. The causation of behaviour is attributed to factors external to the individual. The most influential proponents of the behavioural approach were Ivan Pavlov (1849-1936) who investigated classical conditioning, John Watson (1878-1958) who rejected introspective methods and Burrhus Skinner (1904-1990) who developed operant conditioning. Each of these developments relied heavily on logical positivism purporting that objective 
and empirical methods used in the physical sciences can be applied to the study of consumer behaviour (Eysenck and Keane 2000).

Cognitive Approach: In stark contrast to the foundations of Classical Behaviouralism, the cognitive approach ascribes observed action (behaviour) to intrapersonal cognition. The individual is viewed as an 'information processor' (Ribeaux and Poppleton, 1978). This intrapersonal causation clearly challenges the explicative power of environmental variables suggested in behavioural approaches, however an influential role of the environment and social experience is acknowledged, with consumers actively seeking and receiving environmental and social stimuli as informational inputs aiding internal decision making (Stewart, 1994).

The Cognitive approach is derived in a large part from Cognitive Psychology which can trace its roots back to early philosophers such as Socrates who was interested in the origins of knowledge (Plato 360 B.C.), Aristotle who proposed the first theory of memory (Aristotle 350 B.C.) and Descartes who explored how knowledge is represented mentally in his Meditations (Descartes, 1640: Sternberg, 1996). It was not until the middle of the 21st Century however, that Cognitive Psychology truly emerged as a mainstream and useful field of study with the development of the Stimulus-Organism-Response model by Hebb during the 1950's (Figure 1.1) (Cziko, 2000) and the publication of the landmark text by Ulric Neisser in 1967 (Neisser, 1967). From this point many writers suggested that Cognitivism had taken over from Behaviourism as the dominant paradigmatic approach to decision research (Furedy and Riley, 1987).

Humanistic Approach: The cognitive models appear well covered in generic Consumer Behaviour texts, and are often portrayed as providing the best available explanation of consumer decision making. Despite this, however, there are a growing number of academic writers highlighting limitations of the Cognitive approach and publishing new research attempting to further understanding of specific aspects of behaviour. These new approaches can be described as humanistic as they seek to explore concepts introspective to the individual consumer rather than describe generic processes (Stewart, 1994).

The three most pressing areas for research were identified by Nataraajan \& Bagozzi in 1999. Firstly Cognitive approaches rely upon the assumption of the consumer being a rational decision maker, this appears to neglect the role of emotion in decision making. Nataraajan \& Bagozzi (1999) comment: 'There is a pressing need in the field to balance the rational, cognitive side of marketing thought and practice with new ideas and research on the emotional facets of marketing behavior' (Nataraajan and Bagozzi, 1999 p. 637).

\section{Conceptualization}

Since existing white petroleum transport modes, pipeline, road and railway have different characteristics, market adaptability and advantages, different service attributes of them can be found. Every kind of freight has its own suitable transport mode and OMCs have different degrees of satisfaction when choosing different transport modes. If the satisfied degree of a shipper on a transport mode is higher than another, OMCs think that the utility of the former is better than that of the latter, vice versa.

So the evaluation and choosing probability of OMCs for the three transport modes are discussed and studied based actual investigation and analysis.

Time Factors: The ability to transport product from one point to another as quickly as possible is, by far, the fundamental performance characteristic of transportation. Speed provides the marketing utility of time to distribution and ensures place utility. In detail, the speed of any given transport can be defined as the time required moving product from the production source to a terminal, loading the product onto the transportation vehicle, traversing terminal point, and delivering the products to the receiving terminal. (Ross 2000, p. 590592).

Murphy and Farris (1993) discussed the time-based strategy that was emerging at the time, and its impact on transportation choice with an aim to determine how logistics managers will need to adapt to address a time-based focus in business. This paper is important because it broadened the perspective of this research stream to include other functional areas of the firm, and to focus on integration of carriers through enhanced information technologies such as EDI. The article was largely conceptual, and developed a framework based on a literature review. The authors found that models used for transportation choice should include timeliness and reliability, and suggested that the problem be re-structured so that all factors, including timeliness and reliability, are stated in terms of cost. None of the logistics challenges identified earlier are directly addressed in this research.

The transit time is defined as the total time that elapses from when the consignor makes the goods available for dispatch until the carrier delivers the goods to the consignee (Coyle et al., 1992). As the transit time determines the size of in-transit inventories and influences the amount of stock held by the consignee, the 
transit time can be expressed in terms of inventory carrying cost. Low transit time will reduce the cost of inventory in-transit and also the need to hold stock in distant markets (Christopher et al., 1982).

Some research has found that the transit time reliability or consistency is the most important element in purchasing a carrier's service; see, for example, Raghunathanet al. (1988), Matear and Gray (1993): Saleh and Das (1973). Transit time reliability refers to the degree of variation in shipment delivery time as measured against published or promised schedules (Saleh and Das, 1973), and may also be evaluated in relation to the cost of inventory. Saleh and Das provide an example where the inventory cost of fast but erratic delivery is compared with a slower but reliable service. The survey holds that the consideration of transit time should involve an evaluation of both speed and reliability in the selection of the carrier. The frequency of the transport service is also an important consideration affecting the inventory level. Bagchiet al. (1987) hold that a high frequency transport service often increases transport costs but reduces the cost of inventory.

Cost: The overall transportation cost includes transportation charge, loading and unloading charge and storage cost. The transportation charge is influenced by many factors. For example, if the fixed cost irrelative to the transportation volume occupies large portion in the transportation charge, the transportation frequency will influence the charge. If the carriers make the frequency of transportation higher, the fixed cost will decrease. The transportation charge in Proceedings of the Eastern Asia Society for Transportation Studies, Vol. 5, pp. 16 31,2005 lower when the capacity of vehicle is larger.

Although market time and place utilized are critical elements of transport mode selection, the costs in transportation are equally important. The most obvious cost is the rate paid to the carrier for use of the mode itself. Other indirect costs are labor and material handling to load and unload the carrier, occurrence of spoilage and damage, insurance to protect against possible loss, and in-transit inventory carrying costs paid by the shipper (Ross 2000, p. 590-592).

An area that is often overlooked in carrier selection is the impact of economies of scope (also known as network effects) and economies of scale on carrier choice. Economies of scope are readily apparent relative to the use of transportation equipment after it is emptied. This is also referred to as the empty backhaul, and has been addressed in a general context (Mentzer, 1986), in container-on-barge operations (Choonget al., 2002), in inter-modal railroad-truck transportation (Evers, 1994) and in retail logistics (Dutton, 2003; Byrne, 2004). Economies of scale, on the other hand, are a concern relative to shipment size. There is a strong incentive to ship in full truckloads to minimize the cost associated with the considerable capital expenditure for equipment. Economies of scale are also affected by the handling of inventory - it is cheaper to ship cases than to ship individual units and it is cheaper to ship pallets than to ship individual cases.

A report by a Government appointed committee (Norges Offentlige Utredninger, 1988) showed that the cost of transport and other logistics costs for Norwegian exporters accounted for at least 20 per cent of the value of traditional goods exported from the country. Transport costs alone accounted for 9.2 per cent of the export value or 10.6 per cent including insurance and packing charges. However, the figures ranged widely from wood processing (18.3 per cent) to electronic manufacturing (2.1 per cent). A survey of domestic transport showed that the costs in this trade are even higher, accounting on average for 12.9 per cent of the value (Schultz and Hagen, 1989). The other Nordic countries, Sweden and Denmark have, in comparison, average domestic transport costs of 8.4 and 8.3 per cent respectively, nearly 50 per cent lower than Norway. Schultz and Hagen hold that the difference can be partially explained by the differences in the topography, climate and the transport distances in Norway.

Skarstad (1996) indicates that, in some parts of the transport market, there is a lack of competition because of a limited number of operators. Furthermore, some of the high transport costs can be explained by the imbalance between the inbound and the outbound transport, particularly for general cargo where the sea mode accounts for 72 per cent of the inbound and only 52 per cent of the outbound traffic volume. The capacity is not fully utilized and the result is higher costs.

However, Schultz and Hagen (1989) conclude that 18 per cent of the higher transport cost in Norway, compared with other Nordic countries, could be explained by a lack of organisation of the transport function in companies, and a lack of planning by carriers. The transport cost of exports is slightly more efficient, which may be explained by the importance of maintaining competitiveness in the international market. The equivalent transport costs for competitors in central Western Europe are about 5 per cent of the price of the goods. Schultz and Hagen (1989) compare only the direct cost of transport which, although useful, is of limited value in the context of the total distribution system.

Security: Another important issue that logistics managers face pertains to security in the supply chain, from the perspective of complying with new security measures put in place to reduce terrorist threats, and from the perspective of dealing with the aftermath of a terrorist attack that influences their business operation. An important consequence of the new security measures is an additional \$151 billion annual cost, \$65 billion of 
which is in logistical changes to supply chains (Russell and Saldanha, 2003). OMCs can minimize these impacts by selecting security-conscious carriers, shipping via secure ports, meeting packaging security requirements, and providing background information on key personnel (Rinehart et al., 2004). Furthermore, logistics managers would do well to adjust relations with suppliers and customers, contend with transportation difficulties, and amend inventory management strategies (Sheffi, 2001).

Security factors are concerned with the safe arrival of the goods at the destination point. Bardi (1973) identifies security factors as frequency of damage, ease of claim settlement, and extent of damage. To protect against the opportunity costs of foregone profits through damage or loss, firms often increase the buffer stock resulting in increased inventory costs (Coyle et al., 1992).

Environmental factors: A growing concern over the environment and energy use also presents a challenge to logistics managers. The issues surrounding the environment are certainly broad (Nijkampet al., 1997; Markley and Davis, 2007; Patterson et al., 2008). Environmental impact is of increasing concern to consumers, evidenced by research from LEK Consulting who found that just over half of people in the UK say they "would value details concerning a product's carbon footprint when making a buying decision" (Harvey, 2007a).

Similar in concept to nutritional labels, a carbon footprint label would show consumers how their buying decisions increase or decrease their environmental impact (Harvey, 2007b). Wal-Mart Stores CEO Lee Scott recently addressed 250 supplier CEOs to outline the company's plans to hold them accountable for their "carbon footprints" and excess packaging (Neff, 2007). The transportation sector is a major contributor to air pollution (57 percent of the carbon monoxide), acid rain, maritime water quality problems, and noise (Coyle et al., 2006). Srivastava (2007) identifies a need for integrating environmentally sound choices into supply-chain management research and practice, minimizing the impact of transportation on the environment.

\section{Data Analysis, Presentation and Interpretation}

Response Rate: Response rate refers to a percentage of the subjects that respond to questionnaires (Mugenda \& Mugenda, 1999). The selection of sample size was based on stratified simple random sampling technique drawing from the two categories of OMCs: multinational and independent oil marketers. The questionnaire was distributed randomly to $33 \mathrm{OMCs}$ in the two categories: five (5) multinational and 27 independent OMCs and all responded giving a response rate of $100 \%$. According to Mugenda and Mugenda (2003), a $100 \%$ response rate from the selected sample is good and qualifies to make statistical inferences of the total population. Therefore the response rate for this study was adequate for data analysis. In addition, the researcher targeted to undertake personal structured interviews from the 33 OMCs but managed to interview 18 staff of members, translating into an interview response rate of 54 percent which is also adequate according to Mugenda and Mugenda (2003). The data was analyzed using statistical package for social sciences (SPSS) version 18.

Company's Business Profile : The findings as shown in Figure 4.1 below from the sample size, $3 \%$ have been in the business as oil marketing companies for less one (1) year, 39\% for between one (1) and five (5) years, $36 \%$ for between six (6) and 10 years and about $7 \%$ have been operational for more than 11 years. The name of the respondent was an optional field and $52 \%$ of the respondents indicated their names. The names were for reference in case any further clarification was needed and for the purpose disseminating the survey findings on the areas of interest for the Oil Marketing Companies.

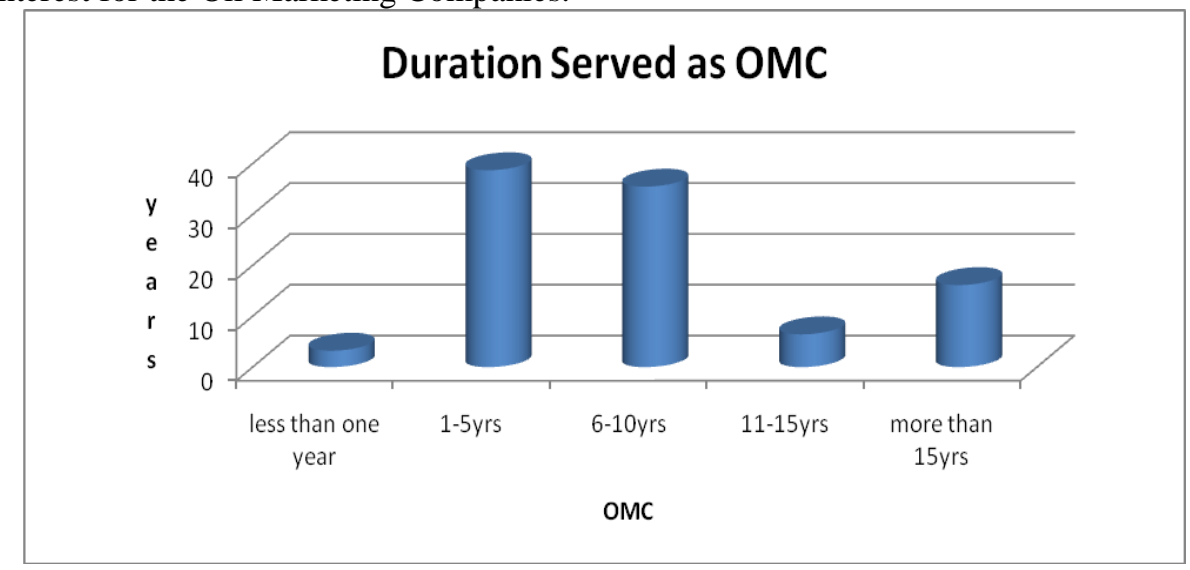

Figure 4.1: Duration Served as OMCs

Business Category: From the survey sample, $56 \%$ of the respondents were multinational oil marketers while

$44 \%$ were independent oil marketers as shown in Figure 4.2 below. However, given that only eight (8) oil marketing companies are registered as multinationals, the response indicates that some of the OMCs are not sure 
of their business category. Hence the research generalized the OMCs in analyzing the determinants of the choice of transportation mode for white petroleum fuels from Mombasa to Nairobi without presenting the findings

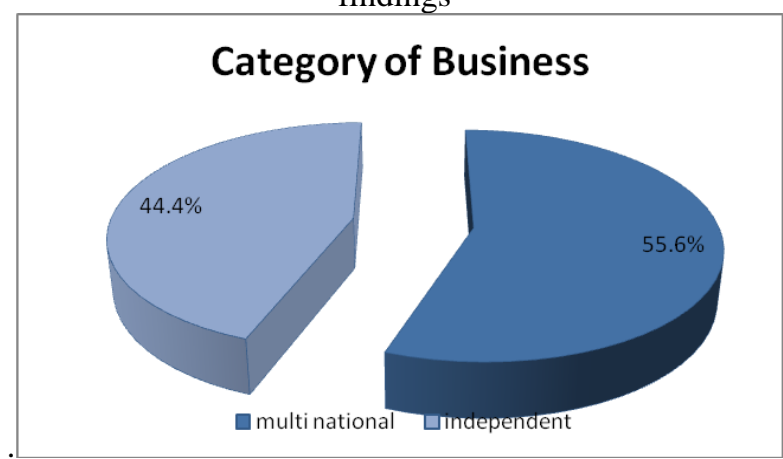

Figure 2: Business Category

The two categories of OMCs have different business operations in terms of policies, operations and scope which could influence the choice of white petroleum transportation mode.

Market Served: The survey established that $90 \%$ of the respondents serve the local market and $94 \%$ serve the export market. Out of these, $79 \%$ of the respondents operate retail outlets in the local market while $59 \%$ have retail outlets the export markets.

The responses indicate that the OMCs serve both the local and export markets in almost equal numbers. Less than $10 \%$ of the respondents concentrate their serves to either the export or the local markets.

Given that $21 \%$ and $41 \%$ of the OMCs do not operate retail outlets in the local and the export markets respectively, it implied that OMCs do business irrespective of having retail outlets.

Choice of Transportation Mode for White Petroleum: The survey sought to establish the mode(s) used by the OMCs in transportation of white petroleum products. As per Figure 4.3 below the findings were that out of the sample, almost all OMCs at $97 \%$ use pipeline, 65\% use road and a small proportion of $14 \%$ of the respondents use rail to transport white petroleum from Mombasa to Nairobi.

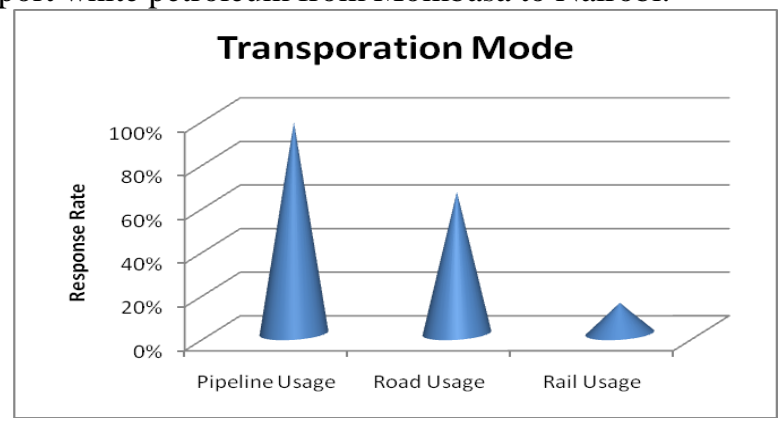

Figure 4.3: Choice of Transportation Mode

From the response on choice of transportation mode, it is evident that pipeline is the most commonly used transportation mode, while there is average usage of road and a small usage of the rail. It can be established that the OMCs use different transportation modes for white petroleum and are not limited to using only one mode.

Frequency of Usage: In terms of frequency of usage, the respondents recorded pipeline average, frequent and high usage at $3 \%, 7 \%$, and $90 \%$ respectively. The use of road was low at $25 \%$, normal at $32 \%$, average at $25 \%$, frequent at $7 \%$ and high usage at $11 \%$. Low usage of rail was highest at $83 \%$ and, normal and frequent usage each at $8 \%$. The usage of different transportation modes is presented in Figure 4.4 below.

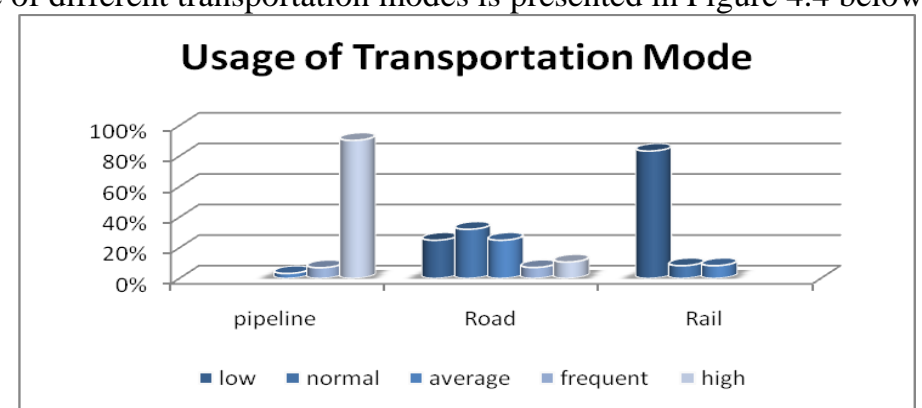

Figure 4.4: Usage of Different Transportation Modes 
From the frequency of using the different transportation modes, the survey established that pipeline is the most commonly used transportation mode for white petroleum. Road is also popular and seems to complement the use of pipeline while rail is a rare alternative.

\section{Reasons for choice of Transportation mode}

The research was to establish reasons for the choice of transportation mode of white petroleum and the responses were as follows:

Volume of Products Handled: With respect to establishing how the volume of products handled affects the choice of transportation mode for white petroleum, $71 \%$ of the sample respondents affirmed that the quantity of products handled determines the choice of transportation mode while $29 \%$ were of the opinion that quantity was not a factor.

From the response, it is observed that to a larger extent, OMCs take into consideration the quantities of fuel transported when selecting the mode of transporting white petroleum from Mombasa to Nairobi.

Ownership of Storage facilities: The survey sought to establish the link between ownership of storage facilities by the OMCs and their choice of transportation mode for white petroleum. Out of the sample, $64 \%$ of the target affirmed to ownership of storage facilities being a reason for the choice of transportation mode while $36 \%$ did not take storage facilities into consideration.

It can therefore be implied that ownership of storage facilities is a determinant of choice of transportation mode for most of the OMCs.

Turn Around Time: The survey sought to establish how different factors affect the turnaround time in doing business and the response was as follows:

\section{How Turnaround Time affects Choice of Transportation Mode}

From the survey sample, $86 \%$ of the respondents said that turnaround time influenced their choice of white petroleum products transportation mode while $14 \%$ said that turnaround time was not a factor taken into consideration.

From the response, it can be deduced that turnaround time is a critical factor to consider while deciding on the mode to use in transportation of white petroleum.

Turn Around of Different Modes: In comparison to the turnaround time by the different transportation modes, 97\% the respondents indicated that pipeline took the longest time while 3\% were of the opinion that pipeline takes a short time. On the use of road, $4 \%$ were of the view that road takes long time, 57\% rated it to take average time while $41 \%$ of the respondents said road takes the shortest time. The shortest turnaround time from the respondents was rail at $95 \%$ while $5 \%$ said it takes average time were $5 \%$.

The findings of the study indicate that there is a relationship between the turnaround time and the choice of transportation mode for white petroleum. From the research, it can be deduced that turnaround time is not a determinant of choice of white petroleum transportation mode from Mombasa to Nairobi given the fact that rail has the shortest turnaround time and it is not a popular mode while pipeline, the commonly used mode, has the longest turnaround time.

Cost of service : With respect to the comparative tariff of the three transportation modes as per Figure 4.5 below, $69 \%$ of the respondents said the pipeline rates were average while $31 \%$ indicated that the pipeline tariff was low. In comparison, road was rated high at $86 \%$ and average at $11 \%$ and low at $3 \%$ while the response for rail tariff was high, average and low at $24 \%, 38 \%$ and $38 \%$ respectively.

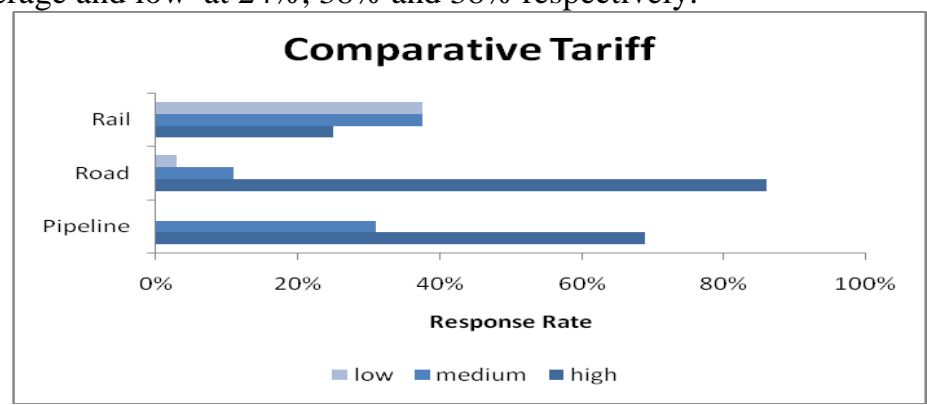

Figure 4.5: Comparative Tariff

In view of the fact that pipeline is the most frequently used transportation of white petroleum and followed closely by road as shown in Figure 4.3, the research established that the OMCs choose a lower tariff as the mode 
of transporting white petroleum from Mombasa to Nairobi. However, given that rail is the cheapest mode of transportation and the least used, it implies that OMCs take into consideration other factors when choosing a mode of transporting white petroleum from Mombasa to Nairobi. A comparative cheaper mode, alongside other qualities of service that assure efficiency is preferred.

Additional Charges: In responding to whether the different transportation modes attract additional charges, $23 \%$ of the respondents said the use of pipeline resulted to additional charges, $96 \%$ were of the opinion that road attracts additional charges and $93 \%$ was as a result of use of rail. From the survey, it is observed that only a few OMCs incur additional expenses by use of pipeline. However, in spite of more having incurred additional expense by the use of road as compared to rail, the use of road still complements pipeline transportation mode.

Losses: In seeking to establish how losses determine the choice of white petroleum transportation mode, from Table 4.1 below $67 \%$ of the sample indicated that there was no loss associated with the use of pipeline, $12 \%$ responded that there were no losses associated with the use of rail $\%$ while $9 \%$ were of the opinion that there were no losses related with the use of road transportation mode.

\begin{tabular}{lllc}
$\begin{array}{c}\text { Table 4.1: Reasons for Losses Associated with } \\
\text { Reasons for Losses }\end{array}$ & \multicolumn{4}{c}{$\begin{array}{l}\text { Different } \\
\text { Response rate in use of the }\end{array}$} \\
& $\begin{array}{l}\text { Pipeline } \\
\text { Road }\end{array}$ & transportation \\
Product loss & $57 \%$ & $64 \%$ & $39 \%$ \\
Insurance costs related to accidents & $6 \%$ & $79 \%$ & $33 \%$ \\
Overtime compensation to staff/millage & $12 \%$ & $64 \%$ & $24 \%$ \\
Pilferage and syphoning of products & $9 \%$ & $79 \%$ & $21 \%$ \\
No loss & $67 \%$ & $9 \%$ & $12 \%$
\end{tabular}

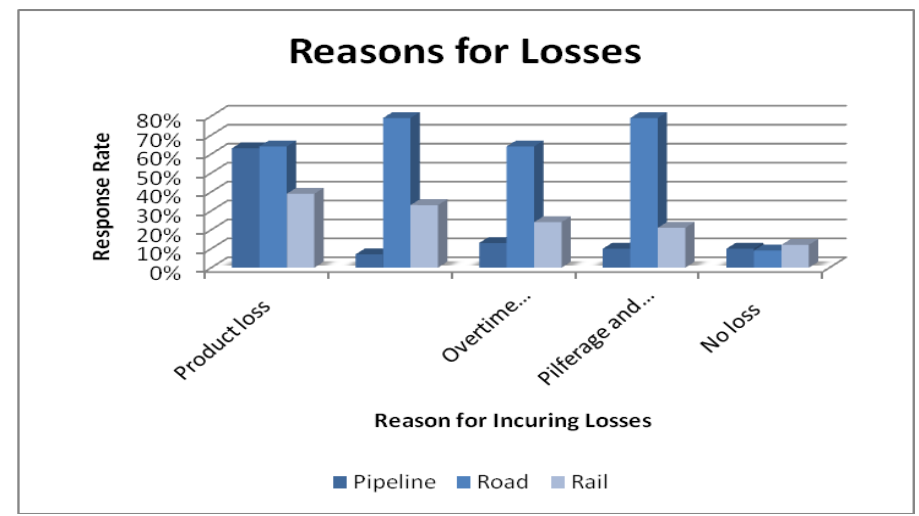

Figure 4.6: Reasons for Losses

From Figure 4.6, the findings indicate that most of the losses incurred are associated with use of road followed by rail and then pipeline. The response rate indicates that the use of pipeline results to minimal losses. However, from the findings as compared to other reasons, product loss was the highest reason for losses associated with the use of pipeline. Only about $10 \%$ of the OMCs or less are of the view that the use of each of transportation modes does not result to losses.

From the findings, it is implied that pipeline is the most frequently used mode of transporting petroleum fuels from Mombasa to Nairobi since it does not attract heavy losses associated with insurance, overtime and pilferage. Even with the high product losses with the use of pipeline, OMCs still prefer using this transportation mode.

Quality of Service: With respect to quality of service as a determinant of choice of white petroleum transportation mode, the response rates and findings are presented in Table 4.2.

Table 4.2: Quality of Service as a Determinant of Transportation Mode

$\begin{array}{llll}\text { Quality of Service } & \text { Pipeline } & \text { Road } & \text { Rail } \\ \text { Quality assurance on products. } & 70 \% & 30 \% & 24 \% \\ \text { Customer complaints on product quality. } & 33 \% & 42 \% & 24 \% \\ \text { Product adulteration } & 21 \% & 51 \% & 18 \% \\ \text { Penalties from the overseeing arms of the government. } & 33 \% & 33 \% & 15 \% \\ \text { Insurance claims } & 30 \% & 46 \% & 21 \%\end{array}$


Based on Figure 4.7 the findings indicate that the major determinant on transportation mode for white petroleum from Mombasa to Nairobi with respect to quality of service is quality assurance of products which presents pipeline as the preferred mode with response rate at $70 \%$.

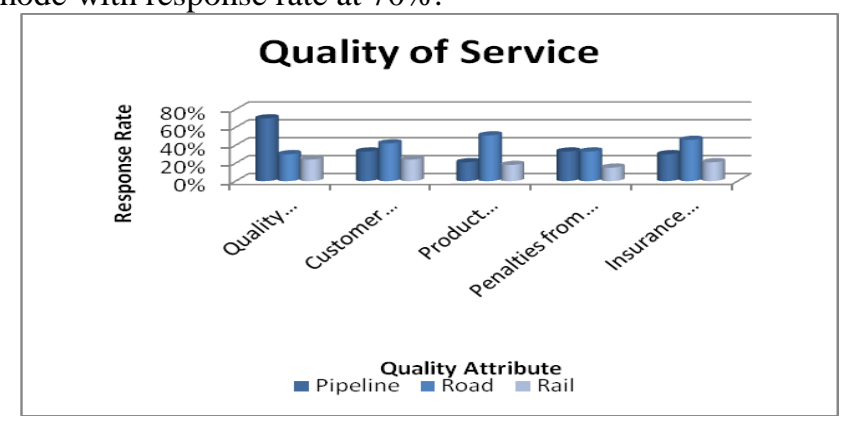

Figure 4.7: Quality of Service of Different Transportation Modes

The findings indicate the response rate on other factors that measure quality of service of transportation of white petroleum products from Mombasa to Nairobi, which customer complaints on product quality, product adulteration, penalties received from the overseeing government bodies and insurance claims are highest with the use of road, followed by pipeline and rail the lowest. These reasons make pipeline a preferred mode of transporting white petroleum from Mombasa to Nairobi. However, even with better services as compared to road transport, rail is not preferred by OMCs in transporting white petroleum from Mombasa to Nairobi.

\subsection{Environmental Factors on Health and Safety}

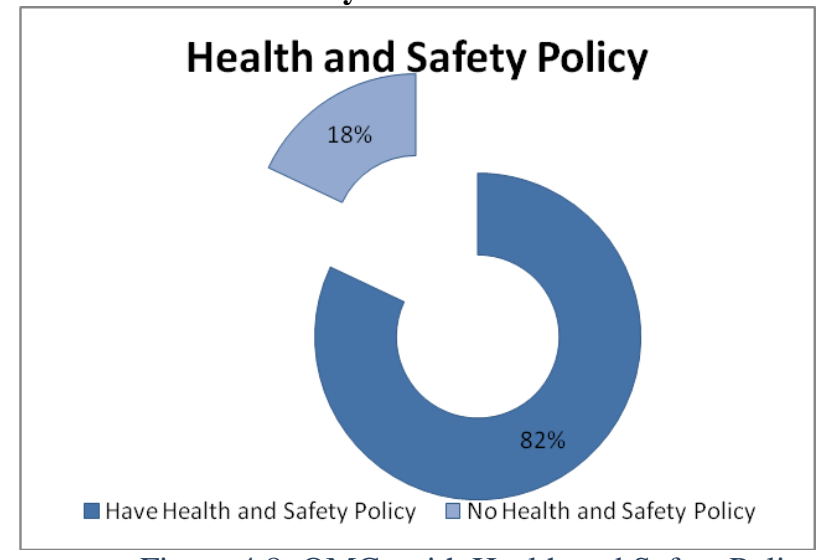

Figure 4.8: OMCs with Health and Safety Policy

The findings indicate from the survey sample in Figure 4.8 above that majority of the target OMCs at $82 \%$ have in place a health and safety policy to guide in operations of handling white petroleum fuels. By extension, it is inferred that the policy guides in transportation of white petroleum fuels and could form a basis of determining the choice of the mode to use in transporting white petroleum fuels from Mombasa to Nairobi.

The response on how different factors attributed to health and safety determine the choice of transportation modes is summarized in Table 4.3.

Table 4.3: Health and Safety Determinants of Choice of Transportation Mode

$\begin{array}{llll}\text { Heath, and safety concerns } & \text { Pipeline } & \text { Road } & \text { Rail } \\ \text { Product adulteration. } & 7 \% & 87 \% & 25 \% \\ \text { Reported accidents. } & 20 \% & 93 \% & 28 \% \\ \text { Government overseeing bodies raising concerns to your company. } & 10 \% & 67 \% & 24 \% \\ \text { Insurance claims } & 7 \% & 70 \% & 21 \% \\ \text { Customer complaints } & 7 \% & 72 \% & 29 \%\end{array}$

From the findings with respect to how different factors related to health and safety influence the choice of transportation mode, the response rates indicate that product adulteration is highest with road at $87 \%$, followed by rail at $25 \%$ and a few at $7 \%$ concerned with the use of pipeline. The response rates on reported accidents were highest at $93 \%$ on the use of road, rail $28 \%$ and pipeline the lowest at $20 \%$. The survey sought to establish how concerns raised by government overseeing bodies with regard to health and safety affect the choice of white petroleum transportation mode and the response rate for road was highest at $67 \%$, rail $24 \%$ and pipeline $10 \%$. 
The sampled OMCs response rate on insurance claims on health and safety associated road usage was highest at $70 \%$, rail $21 \%$ and pipeline $7 \%$ while response on customer complaints was highest with road at $72 \%$, rail $29 \%$ and pipeline $7 \%$.

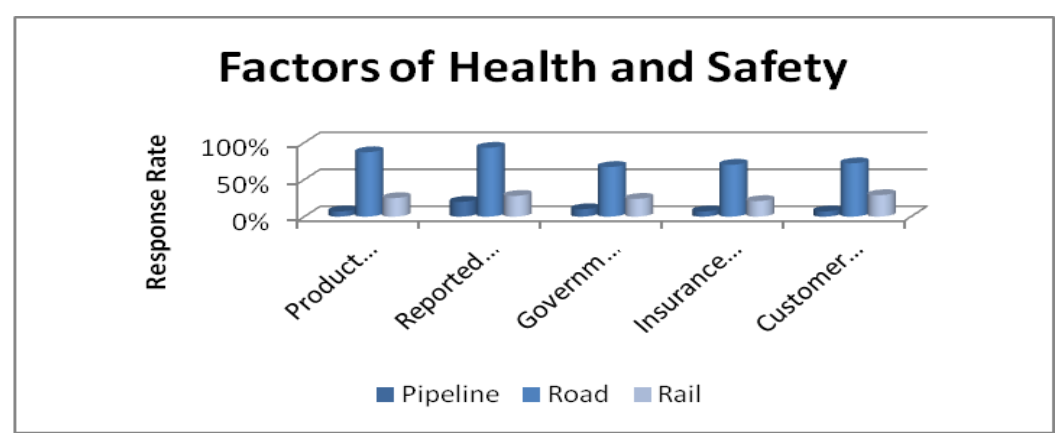

Figure 4.9: Choice of Transportation Mode based on Health and Safety

The findings indicate as depicted in the response rates on Figure 4.9, the use of pipeline in transporting white petroleum fuels from Mombasa to Nairobi has the least health and safety concerns, followed by rail and road having the highest responses on safety concerns.

Based on the responses, it can be deduced that OMCs choose pipeline as a preferred mode of transporting white petroleum fuels from Mombasa to Nairobi due to the health and safety assurance in using the transportation mode. However, road is the next preferred transportation mode irrespective of the mode rated higher with health and safety concerns as compared to rail.

\section{Product Syphoning}

The response rate on product syphoning presented in figure 4.10 indicated that most respondents at 93\% experienced product syphoning when using road to transport white petroleum fuels from Mombasa to Nairobi, 58\% experienced with the use of rail while the lowest response of $15 \%$ was with the use of pipeline.

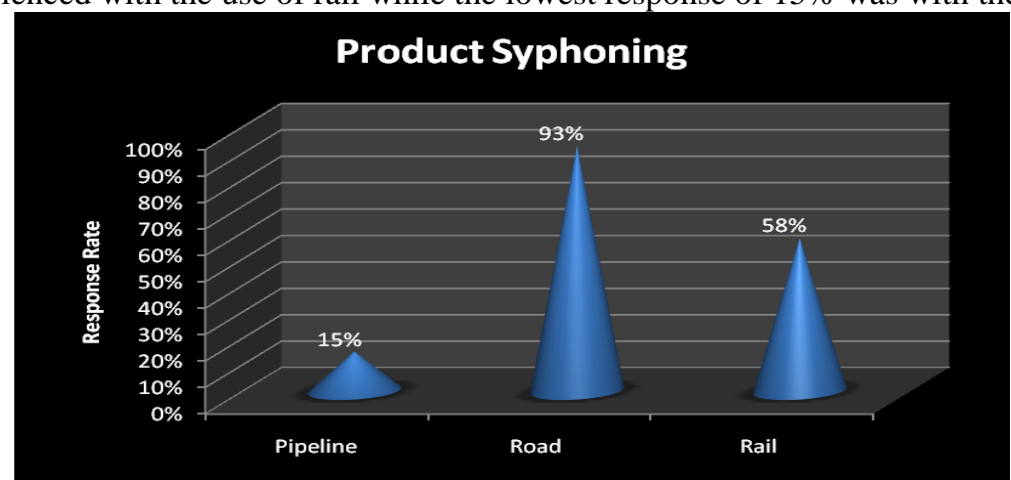

Figure 4.10: Product Syphoning as a Determinant of Transportation Mode

\section{Summary of the findings}

The study found that almost all OMCs at $97 \%$ use pipeline, $65 \%$ use road and a small proportion of $14 \%$ of the respondents use rail to transport white petroleum from Mombasa to Nairobi. The findings also established that the OMCs use different transportation modes for white petroleum and are not limited to using only one mode. The study found out that cost of service, quality of petroleum products delivered and environmental factors on health, safety and security are the key determinants of choice of transportation mode of white petroleum products by OMCs in Nairobi.

Company's Profile: The study established that $56 \%$ of the respondents were multinational oil marketers while $44 \%$ were independent oil marketers. OMCs have almost equal business representation as multinational and independent $\mathrm{OMC}$ hence the business category does not influence their choice of transportation mode for white petroleum fuels from Mombasa to Nairobi. More than half the OMCs have been in business for more than five (5) years which indicates that they have a good appreciation of the business challenges and their experience in the business has an influence in making a choice of the transportation mode to use. Further, the research established that $90 \%$ of the respondents serve the local market and $94 \%$ serve the export market in almost equal proportion. From the findings, $21 \%$ and $41 \%$ of the OMCs do not operate retail outlets in the local and the export markets respectively. This implies that ownership of retail outlets and the market served are not necessarily a basis of deciding which transportation mode to use. 
The survey used the different parameters to measure how the business profile affects the choice of transportation mode of white petroleum products by oil marketers in Nairobi. From the findings of the survey it is concluded that pipeline is the leading mode of choice at $97 \%$ by the OMCs in transporting white petroleum products from Mombasa to Nairobi. The findings also found $65 \%$ use of road transportation could be taken to imply that road closely complements the use of pipeline. The usage of rail is very low and from the responses on the survey, it is clear that in spite of the mode offering better advantages in most of the aspects measured in comparison to pipeline and road, rail is not a preferred transportation mode by the OMCs in Nairobi.

Turnaround Time: The study established there is a relationship between the turnaround time and the choice of transportation mode for white petroleum. From the survey response, $86 \%$ of the respondents said that turnaround time influenced their choice of white petroleum products transportation mode while $14 \%$ said that turnaround time was not a factor taken into consideration. $97 \%$ the respondents indicated that pipeline took the longest time, $4 \%$ were of the view that road takes a long time while $95 \%$ of the respondents said that rail had the shortest turnaround time. However other factors are taken into consideration while using turnaround time as a determinant of transportation mode such as volumes transported where $71 \%$ said it was a factor taken into consideration.

The survey established that ownership of storage facilities gives OMCs flexibility of trading on petroleum products. Based on the interviews conducted, the OMCs with depots have storage facilities in Nairobi and enjoy the preference of loading products as compared to the OMCs without storage facilities who rely on hospitality arrangements and load after the owners of the depots. Therefore the OMCs with depots prefer the use of pipeline since the tariff is low as compared to road and rail. Only in circumstances where pipeline is not able to meet their order demands do they opt to use road to transport white petroleum from Mombasa.

From the survey sample, $86 \%$ of the respondents said that turnaround time influenced their choice of white petroleum products transportation mode, hence deducing that as much as OMCs appreciate that turnaround time is an important factor in making a choice on transportation mode to use, it is considered alongside other factors such as the volumes of products transported by OMCs. This is in view of the fact that pipeline has the longest turnaround time yet it was found to be the preferred mode of transporting white petroleum.

Cost of service : In respect of the comparative tariff, the survey deduces that the OMCs prefer to use a mode of transporting white petroleum from Mombasa to Nairobi which offers lower tariff but also takes into account other qualities of service that assure efficiency. It is also concluded that OMCs prefer to use a transportation mode that does not attract additional charges. The least cost mode was pipeline with $31 \%$ of the respondents indicating that the pipeline tariff was low, road was rated highest at $86 \%$ and rail high at $38 \%$.

Further, the survey subjected the respondents to questions on losses associated with the different transportation modes for white petroleum products that result to additional expenses. The survey established that response rate on additional charges with the use of pipeline was at an average of $21 \%$, road at $59 \%$, and rail at $26 \%$. The survey indicated that pipeline had the least losses associated with insurance cost at seven $7 \%$ compared to road at $79 \%$ and rail at $26 \%$. The response on overtime and millage compensations on staff was rated at $13 \%$ compared to $64 \%$ for road and $24 \%$ for rail. Pilferage and syphoning of products at $10 \%$ compared to $79 \%$ road and $21 \%$ rail. This implies that OMCs choose a transportation mode that assures minimal losses. On the contrary, road at nine (9) \% is still preferred to rail at $12 \%$ in spite of the later attracting lesser losses.

Quality of service: The research measured the quality of service in aspects of quality assurance on products, customer complaints on product quality, product adulteration and penalties from the overseeing arms of the government and insurance claims. Based on the respondents, OMCs in Nairobi take into consideration quality of service when selecting mode of transporting white petroleum. Pipeline offers the highest quality assurance at $70 \%$ and rail usage the least at $24 \%$. Product adulteration, which highly compromises product quality, was highest for road at $51 \%$, pipeline $21 \%$, and rail at $18 \%$. The survey deduces quality of service as a determinant of choice in transportation of white petroleum. However, just like in other considerations, road is preferred to rail regardless of rail offering better quality services.

Environmental Factors: The survey established that health and safety is a key a determinant of the choice of transportation mode for white petroleum products. The study found out that majority of the respondents have in place a health, safety, and security policy to guide in operations of handling white petroleum fuels. It was established that $82 \%$ of the respondents had in place a health, safety, and security policy. The highest concern on health and safety is product adulteration with the highest respondents being road at $87 \%$. In terms of reported accidents, the respondents reported highest concerns for road usage at $93 \%$, rail at $28 \%$, and pipeline at $20 \%$. On average, the response on factors attributed to health and safety for road was at $78 \%$, rail at $25 \%$, and pipeline 
at $10 \%$. However, the more assurance on health and safety by the use of rail at an average of $25 \%$ as compared to road averaged at $78 \%$ does not attract OMCs to use the transportation mode.

\section{Conclusion}

From the survey findings, it is concluded that pipeline is the most preferred transportation mode of white petroleum products by oil marketers in Nairobi. The OMCs consider turnaround time, cost of service, quality of service, and health and safety as a critical factors in determining the choice of transportation mode for white petroleum products from Mombasa to Nairobi. However, the company profile was not a factor in determining the transportation mode.

From the survey responses, it is evident other factors could be making rail not a preferred choice of transportation mode regardless of the responses on most of the attributes indicating rail to offer better quality services as compared to road.

\section{References}

[1]. Abshire, R.D., Premeaux, S.R. (1991), "Motor carrier selection criteria: perceptual differences between OMCs and carriers", Transportation Journal, Vol. 31 No.1, pp.31-5.

[2]. Bechtel, C., Jayaram, J. (1997), "Supply chain management: a strategic perspective", The International Journal of Logistics Management, Vol. 8 No.1, pp.15-34.

[3]. Coulter, R.L., Darden, W.R., Coulter, M.K., Brown, G. (1989), "Freight transportation carrier selection criteria: identification of service dimensions for competitive positioning", Journal of Business Research, Vol. 19 No.1, pp.51-66.

[4]. Cruijssen, F., Dullaert, W., Fleuren, H. (2007), "Horizontal cooperation in transport and logistics: a literature review", Transportation Journal, Vol. 46 No.3, pp.22-39.

[5]. Dobie, K. (2005), "The core shipper concept: a proactive strategy for motor freight carriers", Transportation Journal, Vol. 44 No.2, pp.37-53.

[6]. Foster, J.R., Strasser, S. (1991), "Carrier/modal selection factors: the shipper/carrier paradox", Transportation Research Forum, Vol. 31 No.1, pp.206-12.

[7]. Ireton, S. (2007), "Steps to successful supplier/buyer partnerships", Logistics Today, September, pp.44-6.

[8]. Kent, J.L., Parker, R.S., Luke, R.H. (2001), "An empirical examination of shipper perceptions of service-selection attributes in five truckload industry segments", Transportation Journal, Vol. 41 No.1, pp.27-36.

[9]. Murphy, P.R., Dalenberg, D.R., Daley, J.M. (1991), "Analyzing international water transportation: the perspectives of large US industrial corporations", Journal of Business Logistics, Vol. 12 No.1, pp.169-90.

[10]. Naim, M.M., Potter, A.T., Mason, R.J., Bateman, N. (2006), "The role of transport flexibility in logistics provision", The International Journal of Logistics Management, Vol. 17 No.3,

[11]. Nijkamp, P., Reggiani, A., Bolis, S. (1997), "European freight transport and the environment: empirical applications and scenarios", Transportation Research Part D, Vol. 2 No.4, pp.233-44.

[12]. Pearson, J.N., Semeijn, J. (1999), "Service priorities in small and large firms engaged in international logistics", International Journal of Physical Distribution \& Logistics Management, Vol. 29 No.3, pp.181.

[13]. Pisharodi, R.M. (1991), "The transport-choice decision process: the potential, methodology and applications of script-theoretic modelling", International Journal of Physical Distribution \& Logistics Management, Vol. 21 No.5, pp.13-22.

[14]. Rinehart, L.M., Myers, M.B., Eckert, J.A. (2004), "Supplier relationships: the impact on security", Supply Chain Management Review, Vol. 8 No.6, pp.52.

[15]. Selviaridis, K., Spring, M. (2007), "Third party logistics: a literature review and research agenda", The International Journal of Logistics Management, Vol. 18 No.1, pp.125-50.

[16]. Sheffi, Y., Eskandari, B., Koutsopoulos, H.N. (1988), "Transportation mode choice based on total logistics costs", Journal of Business Logistics, Vol. 9 No.2, pp.137-54.

[17]. MacNealy, Mary Sue. Strategies for Empirical Research in Writing. New York: Longman, 1999. 